\title{
ORIGINAL ARTICLE Pulse blood pressure and cardiovascular mortality in a population-based cohort of elderly Costa Ricans
}

\author{
L Rosero-Bixby ${ }^{1,2}$, F Coto-Yglesias ${ }^{3}$ and WH Dow ${ }^{2}$
}

We studied the relationships between blood pressure (BP), pulse pressure (PP) and cardiovascular (CV) death in older adults using data from 2346 participants enrolled in the Costa Rican CRELES study, mean age 76 years (s.d. 10.2), 31\% qualified as wide PP. All covariates included and analyzed were collected prospectively as part of a 4-year home-based follow-up; mortality was tracked for an additional 3 years, identifying 266 CV deaths. Longitudinal data revealed little change over time in systolic BP (SBP), a decline in diastolic BP, and widening of PP. Wide PP was associated with higher risk of CV death but only among individuals receiving antihypertensive drug therapy. Individuals with both wide PP and receiving therapy had 2.6 hazard rate of CV death relative to people with normal-PP plus not taking treatment (TRT), even adjusting for SBP. Increasing PP between visits was significantly associated to higher CV death independently of TRT status. SBP and DBP were not significantly associated to CV death when the effect of PP was controlled for. Conclusion: elderly hypertensive patients with wide or increasing PP, especially if receiving TRT, are the highest CV risk group, thus must be carefully assessed, monitored and treated with caution.

Journal of Human Hypertension (2016) 30, 555-562; doi:10.1038/jhh.2015.117; published online 17 December 2015

\section{INTRODUCTION}

Cardiovascular (CV) diseases are the main cause of morbidity and mortality globally with hypertension being responsible for about half of deaths due to heart disease and stroke. ${ }^{1}$ Given that blood pressure (BP) in modern populations increases with age, especially in mid-adult ages, prevalence of high BP among elderly people is very high: ${ }^{2}$ about $70 \%$ of Latin Americans aged 70 years or more are hypertensive; ${ }^{3}$ similarly, only $7 \%$ of individuals aged 80 or more had normal BP in the Framingham study. ${ }^{4}$ Prevalence of hypertension is higher in low- and middle-income countries than in the more developed countries ${ }^{5}$ and, because of population aging and behavioral factors such as smoking, salt intake, obesity or reduced physical activity, prevalence of hypertension is increasing globally. ${ }^{6}$ In turn, the nil prevalence of hypertension, and of its increase with age, observed in indigenous populations ${ }^{7}$ suggests that environmental conditions is the primary origin of this modern-world disease.

Although the role of high BP on CV health among the elderly has been well documented in high-income populations, there is scarce data on the prevalence, management and relative importance of different BP indices on CV risk among elderly from low- and middle-income countries. Several studies suggest that the association between BP and adverse CV events differs across elderly populations from different countries, ${ }^{8-10,}$ but the mechanisms are not well understood. In lower income countries, higher mortality due to competing causes, such as infectious diseases and renal diseases, as well as differences in the prevalence of other CV risk factors could reduce or strengthen the relationship between BP and CV mortality. ${ }^{11,12}$

Of particular interest in this study is the relative role of systolic BP (SBP), diastolic BP (DBP) and pulse pressure (PP) in predicting older adult mortality in a developing country context. PP is the difference between SBP and DBP, and has been suggested as an important independent CV risk factor. ${ }^{2,13,14}$ Epidemiological studies have shown that among middle-aged people, SBP and $\mathrm{DBP}$ rise with age in a parallel manner and thus PP is constant over time, but after about age 50 years, only SBP continues to rise and thus a widening PP emerges as a relevant vital sign among older individuals. $^{15}$

The general objective of this article was to identify the association of high BP with CV death in a cohort of elderly Costa Ricans from the population-based panel named 'Costa Rican Longevity and Healthy Aging Study' or CRELES. ${ }^{16}$ A first specific objective was to test the hypothesis that wide PP is an important component of high BP associated with increased risk of CV death in the elderly independently of SBP and DBP. Our second specific objective was to assess the association of changes over time in the components of BP with CV mortality. And third, transversal, specific objective was to assess the modificating effect of antihypertensive drug therapy on the association BP-mortality, as background for future work to refine treatment (TRT) regimens.

The Costa Rican data provide a rare opportunity in that they allow a long-term longitudinal mortality follow-up in a developing country population. Costa Rica is a small middle-income country with a rapidly aging population and a remarkably high life expectancy of 79 years in $2011 .{ }^{17}$ Its public health care and insurance system is near universal, especially for the older population. ${ }^{18}$ Remaining life expectancy of older Costa Rican men is one of the highest in the world due especially to their relatively low CV mortality. ${ }^{19}$ Nevertheless, hypertension prevalence in persons aged 60 years or older is $65 \%$ in Costa Rica $^{20}$ compared with $67 \%$ in the United States. ${ }^{21}$ About half of hypertensive elderly Costa Ricans have their BP under control, whereas one-fourth are unaware of their condition. ${ }^{20}$ An earlier

\footnotetext{
${ }^{1}$ Centro Centroamericano de Población (CCP), Universidad de Costa Rica, San Pedro, Costa Rica; ${ }^{2}$ School of Public Health, the University of California, Berkeley, CA, USA and ${ }^{3}$ Servicio de Geriatría, Hospital Nacional de Geriatría y Gerontología, San José, Costa Rica. Correspondence: Professor L Rosero-Bixby, University of California Berkeley, Department of Demography, 2232 Piedmont Ave Berkeley, CA 94720-2120, USA.

E-mail: Lrosero@mac.com or Lrosero@demog.berkeley.edu

Received 21 July 2015; revised 5 November 2015; accepted 10 November 2015; published online 17 December 2015
} 
analysis of CRELES data on the prospective mortality associated to 22 biomarkers showed little to no association between high baseline BP and mortality. ${ }^{11}$ By focusing in a single biomarker in this article we are now able to improve and expand the analysis of the effect of BP and to pursue our three aforementioned specific objectives. We are also able to improve the methodology in several ways, such as reducing regression dilution biases by including multiple longitudinal BP measures over several years in the CRELES panel, instead of just the baseline values used in the earlier study, as well as reducing reverse causation biases by excluding individuals with serious illness at baseline.

\section{MATERIALS AND METHODS}

\section{Study population}

We used data from the Costa Rican Study on Longevity and Healthy Aging (CRELES), a longitudinal survey of adults aged 60 or more years and residing in Costa Rica, with oversampling of older ages as described elsewhere. ${ }^{16}$ In brief, CRELES selected a probabilistic, nationally representative sample in a multistage sampling process using the 2000 census as sampling frame. Participants were recruited in 2004-2006, mostly in 2005, in baseline, or wave 1, household visits. The study included two additional waves of home-based interviews and physical exams mostly in 2007 and 2009. All participants signed informed consent and the institutional review board of the University of Costa Rica granted human subjects approval. Sampling weight factors correct oversampling and differences in response rates by age, education and region.

\section{Outcome: cardiovascular death}

Our outcome was death caused by CV diseases. CRELES ascertained mortality and cause of death in two ways: (1) through the computer records in the Costa Rica National Death Registry, and (2) during the second and third waves of home visits. The computer follow-up used the unique identification number (the cédula) that all Costa Ricans have. Surviving individuals were followed in the death registry for 3 years after the last visit. The death registry included $>99 \%$ of the deaths identified in the longitudinal home visits; by contrast, $10 \%$ of the deaths from the Registry were not identified in the fieldwork due to losses to follow-up. For the $3 \%$ foreigners in the sample, survival was established only in the field because they do not had a unique identification number with which to link them to the Registry. CV deaths are those with codes I10-I99 (ICD-10) in the main cause of death in the death certificate.

\section{Exposure variables: $\mathrm{BP}$}

Our main exposure variable was wide PP. Trained data collectors took BP in the three CRELES waves with the individual in the sitting position, resting before the measurement, using a cuff located in the right arm and at the heart level, and using the automatic sphygmomanometer OMRON HEM-711AC approved by the European Society of Hypertension International Validation Protocol. ${ }^{22}$ Two measurements $30 \mathrm{~min}$ apart from each other were taken during the interview. We used in the analysis the average of these two measures. PP was computed as the difference between the averaged SBP and DBP, and PP $\geqslant 70 \mathrm{~mm} \mathrm{Hg}$ was considered as 'wide' following Franklin et al. ${ }^{23}$

We focused in the association between PP and CV death that is independent of the effects of SBP or DBP. To model SBP we categorized it into three classes: normal $(<140 \mathrm{~mm} \mathrm{Hg})$, stage- 1 SBP hypertension $(140-159 \mathrm{~mm} \mathrm{Hg})$ and stage-2 SBP hypertension $(\geqslant 160 \mathrm{~mm} \mathrm{Hg})$. DBP was also categorized into three classes: low $(<70 \mathrm{~mm} \mathrm{Hg})$, normal $(70-89 \mathrm{~mm} \mathrm{Hg})$ and high $(\geqslant 90 \mathrm{~mm} \mathrm{Hg})$.

We assessed the effect modification of antihypertensive therapy using the information about medicines CRELES participants were taking in each visit. The data collectors recorded all the medications shown by participants and study physicians coded medicines by type. Participants taking antihypertensive medicines were considered in antihypertensive therapy, regardless of the purpose of the medication. The majority of patients were taking the Ace-inhibitor enalapril (35\%), the calcium channel blocker amlodipine (26\%) or the beta blocker atenolol (22\%). Diuretics were not counted as antihypertensive. We used TRT, instead of diagnosis, status because of the vagueness of the self reported diagnosis status information available in CRELES - some hypertensive individuals were unaware of their condition and some reportedly hypertensive individuals were not in TRT.

The longitudinal design of CRELES allows to identify changes over time in BP for those who were examined in the second or third waves of visits. We established $5 \mathrm{~mm} \mathrm{Hg}$ of annual change as the cut-off to identify meaningful increases or decreases in each of the three components (systolic, diastolic and pulse) of BP as continuous variables. For the TRT condition, we defined the transitions between waves from non-TRT to in-TRT and vice versa.

\section{Other potential confounders}

We used the CRELES participants' information on gender, residence in the great metropolitan area of San Jose, years of attained education, selfassessed economic situation in three categories, self-assessed health status as fair or bad, active smoking and body mass index categories for controlling their potential confounding of the relationship between BP and mortality. Participants with baseline reported history of heart attack, stroke or cancer were excluded from the mortality analysis to reduce reverse causation bias. ${ }^{24}$ We used the exact dates of birth, death and visits in the three waves to establish age and survival time. Date of birth, and thus age, did not come from self-report but from the Costa Rican identification card (the cédula) validated with the civil registration databases. With the exception of sex and education, all variables, including BP measures, were taken as time-varying covariates with values updated with the information from the most recent interview.

\section{Statistical analysis}

We set the survival-time data with age as the time scale (instead of time as the baseline) as recommended for events like death in which age is more important than time in the study. ${ }^{25}$ The entry point into observation was the date of the baseline visit. The exit point was the date of death or at 3 years after the last visit for survivors. Non-CV deaths were considered as censored observations at the date of death. BP and the other time-varying variables were updated at the date of follow-up visits.

We modeled CV death with parametric proportional hazard models, assuming a Gompertz distribution, which is known to describe well human mortality at old ages. ${ }^{26}$ To model age accurately, we fragmented the time observed for each individual into 1-year-age segments. On average, there were 5.0 segments per individual. We used the STATA MP 12 software (StataCorp LP, College Station, TX, USA) to estimate hazard regression models. All s.e. are robust estimates that correct the lack of independence of the several observations for the same individual. Sampling weights were used in all statistical analyses.

Because PP is a linear combination of SBP and DBP, the three BP components cannot be included in a single model. Therefore, to assess the independent effect of PP we estimated two models: one including PP and SBP and another including PP and DBP.

To show estimates for the general population, all prevalence estimates, and crude CVD-death rates, were computed using all the observations available in CRELES, without the exclusion of seriously ill individuals.

\section{Sensitivity analysis}

To check whether the so called 'white coat bias' (that is, the first measurement of BP tend to be upward biased ${ }^{27}$ ) affected our main results we re-estimated them using only the second BP measurement in each visit. To check for detection biases (that is, deaths of hypertensive, and especially in TRT, individuals could be more likely to be classified as CV deaths), we re-estimate our main models for non-CV death as outcome. We also checked the sensitivity of our main results to the use of different cut-offs for wide PP: 65 and 75, instead of $70 \mathrm{~mm} \mathrm{Hg}$, as well as to the use of models different than Gompertz regression.

\section{RESULTS}

Participants and their characteristics

The 2827 participants in the original CRELES were $85 \%$ of those included in the sample. The bias from higher non-response rates among younger, urban, more affluent individuals was corrected by the sampling weights. In the main analysis of the association of BP and prospective CV mortality, we excluded 46 (2\%) individuals with missing variables and 435 (15\%) individuals who reported 


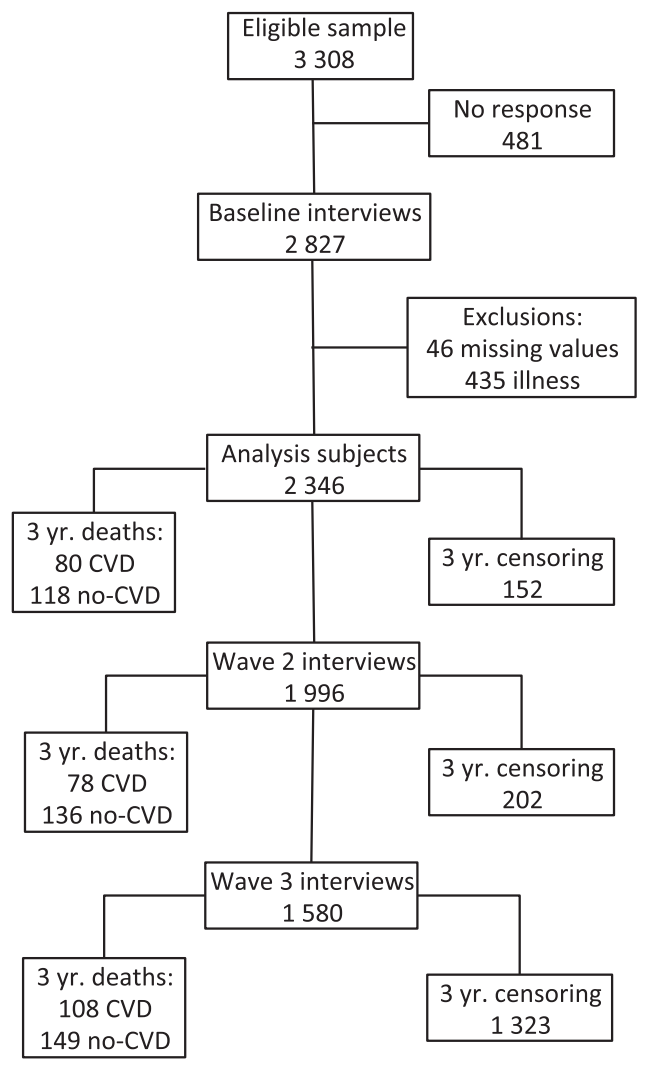

Figure 1. Flowchart of CRELES data used in the main analyses.

stroke, heart disease or cancer at baseline. The flowchart in Figure 1 shows the numbers of participants and outcomes in the different stages of this longitudinal survey. To estimate the effect of BP levels on mortality our analytical sample size comprised 2346 individuals and $266 \mathrm{CV}$ deaths. To estimate the effect of BP changes, the sample was restricted to individuals with at least two interviews: $N=1996$ and 186 CV deaths. Subjects were visited 2.5 times on average for a mean of 5.1 observation-years.

As shown in Table 1, our main exposure condition-wide PP-included 883 (31\%) of participants at baseline (741 after exclusions). About one third of this population was aged 75 years or more after correcting for sampling weights $(55 \%$ were $>75$-yearsold in the non-weighted sample). The proportion of older individuals was substantially higher in the wide-PP group. Women outnumber men, as usual in an elderly population. About half of this population lived in the great metropolitan area of the capital city. Educational level was low: only $49 \%$ had complete elementary school or higher. About $45 \%$ of participants self-assessed their economic situation as good or excellent, but $44 \%$ reported poor or fair health. Less than 10\% were active tobacco smokers and $23 \%$ were obese with a body mass index of $30 \mathrm{Kg} \mathrm{m}^{-2}$ or higher.

\section{Blood pressure}

Almost half (48\%) of this population had antihypertensive TRT prescriptions (Table 1); this proportion was higher $(60 \%)$ in the wide-PP group. More than half of the entire sample meet the criteria for high SBP (SBP $\geqslant 140 \mathrm{~mm} \mathrm{Hg}$ ); of these, 31\% have SBP indicating stage-1 hypertension (SBP $140-159 \mathrm{~mm} \mathrm{Hg}$ ) and $22 \%$ are in stage 2 (SBP $\geqslant 160 \mathrm{~mm} \mathrm{Hg}$ ). There was considerable co-occurrence of stage- 2 high SBP and wide PP: $62 \%$ of wide-PP individuals were in stage-2 high SBP compared with 4\% high SBP among the normal-PP group.

Eighteen percent of the entire sample had low DBP $(\mathrm{DBP}<70 \mathrm{~mm} \mathrm{Hg})$. Notably, only $3 \%$ of the sample would be

\begin{tabular}{|c|c|c|c|c|}
\hline Characteristics & $\begin{array}{l}\text { Entire } \\
\text { sample }\end{array}$ & $P P<70 \mathrm{~mm} \mathrm{Hg}$ & $\begin{array}{l}\text { Wide } \\
\text { PP }\end{array}$ & $\begin{array}{l}\mathrm{t} \text {-test of } \\
\text { difference }\end{array}$ \\
\hline ( $N$ at baseline) & $(2827)$ & (1908) & $(883)$ & \\
\hline \multicolumn{5}{|l|}{ Potential confounders } \\
\hline Aged 75+ & 32.2 & 27.4 & 43.1 & $9.46^{* *}$ \\
\hline Male & 47.3 & 49.0 & 43.3 & $-2.89^{* *}$ \\
\hline $\begin{array}{l}\text { Lives in Metro San } \\
\text { Jose }\end{array}$ & 51.0 & 50.8 & 51.5 & -1.44 \\
\hline $\begin{array}{l}\text { Completed primary } \\
\text { school }\end{array}$ & 49.0 & 52.7 & 40.6 & $-6.52^{* *}$ \\
\hline $\begin{array}{l}\text { Good/ excellent SA } \\
\text { economic status }\end{array}$ & 45.4 & 45.4 & 45.6 & -0.16 \\
\hline Poor/fair SA health & 44.3 & 43.7 & 45.7 & 1.42 \\
\hline Current smoker & 8.9 & 8.6 & 9.7 & 1.05 \\
\hline $\mathrm{BMI}<18.5 \mathrm{Kg} \mathrm{m}^{-2}$ & 3.0 & 3.2 & 2.6 & -0.32 \\
\hline $\mathrm{BMI} \geqslant 30 \mathrm{Kg} \mathrm{m}^{-2}$ & 23.0 & 22.8 & 23.2 & 0.25 \\
\hline \multicolumn{5}{|l|}{$B P$ indicators } \\
\hline In TRT & 47.8 & 42.3 & 60.2 & $9.9^{* *}$ \\
\hline $\begin{array}{l}\text { Stage } 1 \text { high SBP } \\
140-159 \mathrm{~mm} \mathrm{Hg}\end{array}$ & 31.3 & 30.2 & 33.8 & $2.4^{*}$ \\
\hline $\begin{array}{l}\text { Stage } 2 \text { high SBP } 160 \\
+\mathrm{mm} \mathrm{Hg}\end{array}$ & 21.7 & 4.1 & 61.6 & $42.57^{* *}$ \\
\hline $\begin{array}{l}\text { Low DBP } \\
<70 \mathrm{~mm} \mathrm{Hg}\end{array}$ & 17.6 & 19.2 & 14.0 & $-4.57^{* *}$ \\
\hline High DBP $90+m m ~ H g$ & 22.0 & 18.2 & 30.6 & $8.43^{* *}$ \\
\hline Wide PP $70+\mathrm{mm} \mathrm{Hg}^{2}$ & 30.5 & 0.0 & 100.0 & \\
\hline \multicolumn{5}{|l|}{ BP changes between visits } \\
\hline Declined SBP & 29.7 & 22.3 & 50.3 & $15.56^{* *}$ \\
\hline Increased SBP & 30.0 & 34.4 & 17.3 & $-10.48^{* *}$ \\
\hline Declined DBP & 29.5 & 26.3 & 38.4 & $6.48^{* *}$ \\
\hline Increased DBP & 12.6 & 13.1 & 11.0 & -1.74 \\
\hline Declined PP & 18.1 & 11.1 & 37.7 & $15.15^{* *}$ \\
\hline Increased PP & 32.6 & 37.1 & 19.8 & $-10.37^{* *}$ \\
\hline TRT to no-TRT & 4.0 & 3.4 & 5.3 & 1.71 \\
\hline No-TRT to TRT & 9.9 & 8.5 & 13.4 & $4.11^{* *}$ \\
\hline $\begin{array}{l}\text { Abbreviations: } B M I \text {, body } m \\
\text { PP, pulse BP; SA, self asses } \\
\text { tensive treatment. Declined } \\
\text { and wave } 3 \text { vs } 2 \text { ) was } \geqslant 15 \\
\text { sampling weights and the } \\
{ }^{*} P<10.05 \mid,{ }^{*} P<10.011 .\end{array}$ & $\begin{array}{l}\text { lass index } \\
\text { sed; SBP, } \\
\text { /increase } \\
\mathrm{mm} \mathrm{Hg} \\
\text { informat }\end{array}$ & $\begin{array}{l}\text {; BP, blood pressu } \\
\text { systolic BP; TRT, } \\
\text { d if change betwe } \\
\text { per year. Proportic } \\
\text { ion of the three }\end{array}$ & $\begin{array}{l}\text { re; DB } \\
\text { receivi } \\
\text { en vist } \\
\text { on cor }\end{array}$ & $\begin{array}{l}\text { diastolic BP, } \\
\text { g antihyper- } \\
\text { (wave } 2 \text { vs } 1 \\
\text { puted using } \\
\text { Significance: }\end{array}$ \\
\hline
\end{tabular}

considered to have low DBP if the cut-off had been set at 60 $\mathrm{mm} \mathrm{Hg}$. Contrary to expectations, low DBP is moderately less common among wide-PP individuals (19 vs $14 \%$ ). High DBP was a less common contributor to measured hypertension than was high SBP: high DBP affected only $22 \%$ of this population (and among those with wide PP, still just $31 \%$ had high DBP).

With the $5 \mathrm{~mm} \mathrm{Hg}$ of annual change as the cut-off to identify meaningful increases or decreases in $\mathrm{BP}$, we found that the same proportion (30\%) decreased or increased their SBP between waves (lowest panel in Table 1). In contrast, the predominant change in DBP was decline: $30 \%$ compared with $13 \%$ with increased DBP. Correspondently with DBP changes, the predominant PP change was increase - 33\% compared with $18 \%$ with decreasing PP. Although $10 \%$ of participants initiated therapy between visits, $4 \%$ stopped it. BP changes differed significantly by initial PP status: wide-PP individuals were more likely to reduce their PP and their SBP and to rise their DBP in what looks like a regression to mean change

Figure 2 shows the sample's distribution (smoothed out with a kernel algorithm implemented in STATA) by the readings in SBP, 

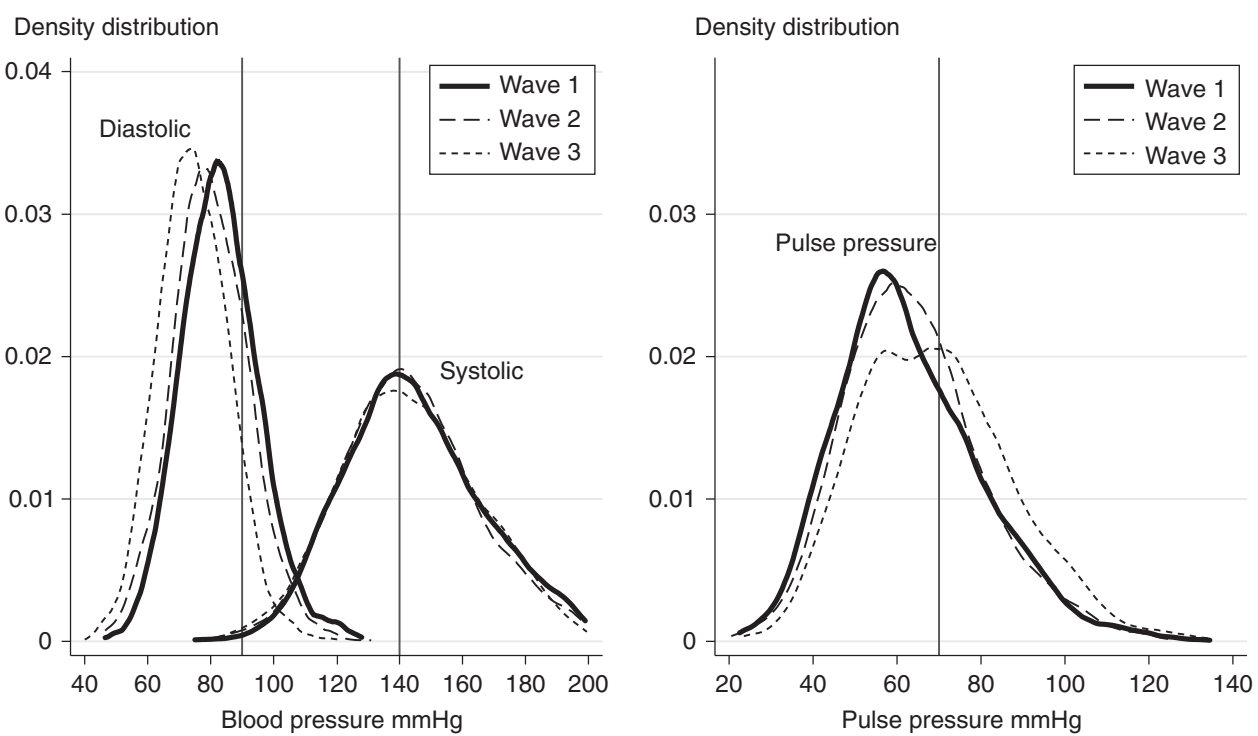

$\mathrm{N}=1,854$

Figure 2. Density distribution of systolic and pulse BP measurements by CRELES wave for participants in all three waves.

\begin{tabular}{|c|c|c|c|c|c|c|c|}
\hline$N$ & & & & 7269 & & 7286 & \\
\hline Total & 14554 & 13 & $(12-15)$ & 7 & $(6-9)$ & 20 & $(17-24)$ \\
\hline \multicolumn{8}{|l|}{ SBP } \\
\hline S1 high SBP $140-159$ & 4576 & 12 & $(9-15)$ & 8 & $(5-12)$ & 15 & $(11-21)$ \\
\hline S2 high SBP $160+$ & 3441 & 20 & $(15-26)$ & 8 & $(5-14)$ & 27 & $(21-37)$ \\
\hline \multicolumn{8}{|l|}{$D B P$} \\
\hline Low DBP $<70 \mathrm{~mm} \mathrm{Hg}$ & 3121 & 19 & $(15-25)$ & 8 & $(5-13)$ & 32 & $(25-43)$ \\
\hline Normal DBP 70-89 & 8461 & 12 & $(10-14)$ & 7 & $(5-10)$ & 17 & $(14-22)$ \\
\hline High DBP 90+ & 2762 & 11 & $(8-16)$ & 6 & $(3-13)$ & 15 & $(10-24)$ \\
\hline \multicolumn{8}{|l|}{$P P$} \\
\hline
\end{tabular}

Abbreviations: BP, blood pressure; $C V$, cardiovascular; $C l$, confidence interval; DBP, diastolic BP; PP, pulse BP; SBP, systolic BP; TRT, treatment. N, 2827 subjects (2801with BP information), 14554 years, 357 CV deaths rates corrected for sampling weights.

DBP and PP in each wave of visits. Only individuals with measures in the three waves were represented in the figure; that the three curves are for exactly the same group of individuals and the wave's changes are exclusively due to the passage of time or the ageing of the group (cohort and survival-selection effects are thus controlled). The CRELES' data follows the expected normal-shape distribution in the BP measures. The panel's distribution by SBP did not change across waves. In contrast the DBP distribution shifted to the left with passage of time and the PP distribution shifted to the right. These data thus suggest that aging in this group of elderly Costa Ricans altered little their SBP as a population, whereas it reduced DBP and widened PP.

BP levels and CV mortality

The crude CV mortality rate in this population was 13 annual deaths per 1000 individuals (Table 2). Among those in TRT or in stage-2 high SBP or with low DBP or with wide-PP the death rate was clearly higher: about 20 per 1000. In the other marginal groups in Table 2 the rate ranges between 7 and 12 per 1000. The lowest rate (seven per 1000) was for individuals who were not in TRT. Stratification by being in TRT revealed that large differences in mortality occured only among people in TRT, in contrast with almost no mortality differences among people not in TRT. For example, crude CV mortality among people in TRT was 32 for those with $\mathrm{DBP}<70 \mathrm{~mm} \mathrm{Hg}$ compared with 15 per 1000 among those with high DBP, while the corresponding rates for those not in TRT were 8 and 6 , respectively.

The hazard regression estimates simultaneously control the confounding effect of age, sex and some socioeconomic and health characteristics. Table 3 shows the results for BP components from three regression specifications. The first model, which consists of a traditional specification that includes SBP, DBP and TRT, shows that in this elderly population stage-2 high-SBP 
Table 3. CV death HR of BP levels and TRT. Gompertz regression models

\begin{tabular}{|c|c|c|c|c|c|c|}
\hline \multirow[t]{2}{*}{$B P$ and $T R T$} & \multicolumn{2}{|c|}{ Traditional model } & \multicolumn{2}{|c|}{ SBP-PP model } & \multicolumn{2}{|c|}{$D B P-P P$ model } \\
\hline & $H R$ & $(95 \%$ Cl) & $H R$ & $(95 \%$ Cl) & $H R$ & $(95 \%$ Cl) \\
\hline \multicolumn{7}{|l|}{ SBP } \\
\hline Normal $<140 \mathrm{~mm} \mathrm{Hg}$ & 1 & Ref. & 1 & Ref. & & \\
\hline Stage 1 high $140-159$ & 1.02 & $(0.70-1.50)$ & 0.81 & $(0.53-1.23)$ & & \\
\hline Stage 2 high $160+$ & $1.89^{* *}$ & $(1.20-2.98)$ & 1.13 & $(0.70-1.82)$ & & \\
\hline Low DBP $<70 \mathrm{~mm} \mathrm{Hg}$ & 1.25 & $(0.86-1.81)$ & & & 1.10 & $(0.79-1.54)$ \\
\hline Normal DBP $70-89$ & 1 & Ref. & & & 1 & Ref. \\
\hline High DBP 90+ & $0.61+$ & $(0.36-1.03)$ & & & 0.78 & $(0.49-1.23)$ \\
\hline In TRT & $2.04^{* *}$ & $(1.49-2.78)$ & & & & \\
\hline \multicolumn{7}{|l|}{$P P$ and TRT } \\
\hline
\end{tabular}

individuals had 1.89 risk of CV death compared with normal SBP individuals while stage- 1 high-SBP individuals did not differ in their CV mortality from those with normal SBP. High DBP seems to reduce the $\mathrm{CV}$ hazard to 0.61 (marginally significant effect at $P=0.06$ ). The risk of individuals taking antihypertensive medicines more than doubled the risk of those not taking medicines.

The second and third model specifications in Table 3 included PP in interaction with the indicator of being in TRT. Adding into the model the effect of PP turned non-significant the associations of DBP or SBP with CV mortality originally observed in the traditional specification. Instead, PP emerged with independent and significant CV mortality effects. The highest CV mortality occured in the group with wide PP and in TRT: 2.82 hazard ratio (HR) relative to the group with normal PP and not in TRT (when DBP was included in the regression), or $2.58 \mathrm{HR}$ when SBP was included in the regression. However, CV mortality in wide-PP individuals did not differ from mortality of those with normal PP among those not taking antihypertensive TRT. If they were in TRT, wide PP was associated with a significant HR of 1.66 compared with normal PP (when DBP was included in the regression), or HR of 1.53 with SBP in the regression.

The possibility of effect modifications by DBP or SBP to the described associations of PP with CV death were not supported by the data. No interaction terms of PP with SBP or DBP categories were statistically significant when added to the models in Table 3 (results not shown).

\section{BP changes over time and CV mortality}

Table 4 shows the estimated effects of changes in BP between visits over prospective CV mortality in addition to BP levels in the starting point of the interval. Only individuals with at least two visits were included, which reduced the number of individuals to 1997. The analysis was stratified by the condition: receiving antihypertensive TRT in the first node of the interval. Only relevant categories of SBP and DBP were modeled as initial levels: stage-2 high SBP ( $\geqslant 160 \mathrm{~mm} \mathrm{Hg}$ ) and low DBP ( $<70 \mathrm{~mm} \mathrm{Hg})$. Increased PP resulted consistently and significantly associated to higher CV death in the two TRT categories and either in the model with high SBP or in the model with low DBP. The HR of increased PP was 2.6 in the model with SBP and 2.2 in the model with DBP relative to individuals with no change in PP and not in TRT in the initial visit. Starting TRT resulted also significantly associated to higher CV mortality. But the reverse, stopping TRT, was not. Having a wide PP at the beginning of the interval was strongly associated to higher CV death but only in the group receiving therapy, confirming the initial results. SBP and DBP levels and changes were not significantly associated to CV death in these models.

\section{Sensitivity analyses}

Our main results (Table 3 ) were not sensitive to alternate specifications (Cox regression and Weibull survival distribution models) to our Gompertz regression models (results not shown in tables). Neither, using different cut-offs to define wide-PP altered qualitatively our main results. For example, the HR of 2.58 of wide PP and in TRT individuals in Table 3 was 2.26 for a $65 \mathrm{~mm} \mathrm{Hg}$ PP cut-off and 2.41 for a 75 cut-off.

Using only the second BP measurement to avoid white coat bias resulted in slightly lower BP readings that reduced the estimated prevalence of high SBP by 1.5 percentage points and that of wide PP by 0.7 points. However, the associations with CV mortality did not changed qualitatively (results shown as Supplementary Information, Supplementary Table SI-2 mirroring Table 3).

Neither individuals receiving antihypertensive TRT nor those with wide-PP showed significantly reduced non-CV mortality, which would had been indication of detection biases in the classification of deaths as of CV origin (results included as Supplementary Information in Supplementary Table SI-2, which mirrors Table 3).

\section{DISCUSSION}

CRELES data for a unique population of elderly individuals from a middle-income country have shown that elderly Costa Ricans with a wide PP $(\geqslant 70 \mathrm{~mm} \mathrm{Hg})$ and in TRT with antihypertensive medicines were clearly at elevated risk of CV death: HR of 2.6 relative to individuals with normal PP and not in TRT (even after including SBP as a covariate in the regression) and HR 1.5 relative 
Table 4. CV death HR of levels and changes in BP by TRT status. Gompertz regression models

\begin{tabular}{|c|c|c|c|c|}
\hline \multirow[t]{2}{*}{ BP levels and changes } & \multicolumn{2}{|c|}{ No TRT $\mathrm{N}=1157$} & \multicolumn{2}{|c|}{$T R T^{\mathrm{a}} \mathrm{N}=840$} \\
\hline & $H R$ & $(95 \% \mathrm{Cl})$ & $H R$ & $(95 \% \mathrm{Cl})$ \\
\hline \multicolumn{5}{|l|}{ SBP and PP model } \\
\hline $\begin{array}{l}\text { Stage } 2 \text { high SBP } \\
\text { Wide PP }\end{array}$ & $\begin{array}{c}2.22+ \\
0.94\end{array}$ & $\begin{array}{l}(0.89-5.51) \\
(0.34-2.58)\end{array}$ & $\begin{array}{c}0.89 \\
2.59^{* *}\end{array}$ & $\begin{array}{l}(0.50-1.57) \\
(1.46-4.58)\end{array}$ \\
\hline \multicolumn{5}{|l|}{ Change between visits } \\
\hline Decreased & 1.41 & $(0.62-3.17)$ & 1.50 & $(0.76-2.97)$ \\
\hline Increased & 0.93 & $(0.41-2.11)$ & 0.93 & $(0.47-1.84)$ \\
\hline \multicolumn{5}{|l|}{$P P$} \\
\hline Decreased & 0.80 & $(0.32-2.02)$ & 0.86 & $(0.46-1.61)$ \\
\hline Increased & $2.59^{*}$ & $(1.23-5.48)$ & $2.09 *$ & $(1.09-3.99)$ \\
\hline \multicolumn{5}{|l|}{ TRT } \\
\hline Started & $1.96+$ & $(0.98-3.90)$ & NA & \\
\hline Stopped & NA & & 1.10 & $(0.56-2.16)$ \\
\hline \multicolumn{5}{|l|}{$D B P$ and $P P$ model } \\
\hline Low $(<70)$ DBP & 1.05 & $(0.50-2.20)$ & 1.43 & $(0.85-2.42)$ \\
\hline Wide PP & 1.57 & $(0.77-3.22)$ & $2.51^{* *}$ & $(1.53-4.14)$ \\
\hline \multicolumn{5}{|l|}{ Change between visits } \\
\hline \multicolumn{5}{|l|}{$D B P$} \\
\hline Decreased & 1.49 & $(0.76-2.92)$ & 1.19 & $(0.71-1.99)$ \\
\hline Increased & 0.97 & $(0.27-3.50)$ & 0.80 & $(0.43-1.49)$ \\
\hline \multicolumn{5}{|l|}{$P P$} \\
\hline Decreased & 0.96 & $(0.39-2.38)$ & 1.01 & $(0.56-1.84)$ \\
\hline Increased & $2.20^{*}$ & (1.08-4.49) & $1.76^{*}$ & $(1.05-2.96)$ \\
\hline \multicolumn{5}{|l|}{ TRT } \\
\hline Started & $2.07^{*}$ & $(1.02-4.20)$ & NA & \\
\hline Stopped & NA & & 1.11 & $(0.56-2.19)$ \\
\hline \multicolumn{5}{|c|}{$\begin{array}{l}\text { Abbreviations: } \mathrm{BP} \text {, blood pressure; } \mathrm{CV}, \quad \text { cardiovascular; } \mathrm{Cl} \text {, confidence } \\
\text { interval; DBP, diastolic BP; HR, hazard ratios; } \mathrm{NA} \text {, not appliable; PP, pulse BP; } \\
\text { SBP, systolic BP; TRT, treatment .Controlled for age, sex, region, smoking, BMI } \\
\text { classes, education, and self assessed health \& economic situation. Sampling } \\
\text { weights included. Significance: }{ }^{*} P<10.051, \quad{ }^{* * P} P<10.011, \quad+P<10.101 \text {. } \\
\text { 'Decreased' and 'increased' are changes } \geqslant 15 \mathrm{~mm} \mathrm{Hgl} \text { per year. 'In TRT if } \\
\text { taking hypertension medicines at the begining of the two-visit interval. } \\
\text { People in TRT had a HR=2.59 compared with those no in TRT. }\end{array}$} \\
\hline
\end{tabular}

to normal-PP individuals in TRT (HRs were 2.8 and 1.7, respectively, if DBP was included in the regression instead of SBP). Prospectively, individuals with widened PP by $5 \mathrm{~mm} \mathrm{Hg}$ or more per year showed also a higher CV mortality independently of their TRT status and their initial levels and changes in SBP and DBP. The associations of SBP and DBP with CV death usually disappear when PP is taken into account, especially when recent changes in PP are considered.

In addition to $\mathrm{PP}$, receiving antihypertensive therapy was consistently and significantly associated to higher risk of CV death. Being an observational study, we cannot make causal inferences from this result regarding TRT effectiveness. We cannot distinguish whether clinicians are efficiently targeting the highest risk individuals with TRTs that are lowering risks from even higher levels that they might have experienced in the absence of TRT, vs the alternative hypothesis that TRT regimens are poorly titrated thus have little effect, vs the less likely hypothesis that the TRTs are harmful in this population. An alternative hypothesis is that despite best efforts, TRT regimens were unable to effectively target an underlying cause of increased CV mortality risk, that is, widened PP. Distinguishing between these hypotheses will require future research. However, we can say with confidence that the data show the need to critically examine antihypertensive TRT protocols for older adults in this and similar populations, as well as the need to monitor health and TRT compliance of elderly patients taking antihypertensive medicines who have wide or increasing PP.

In Costa Rica, according to CRELES, about 30\% of females and $20 \%$ of males in their eighties fall in the group of high risk of CV death, that is, with wide PP and receiving antihypertensive TRT. These proportions double those observed by age 60 years.

DBP of the cohort tends to decline over time and high DBP was not associated with higher risk of CV death. In contrast, SBP stays constant over time in the cohort, which may be in part result of successful antihypertensive TRTs. The fact that BP does not necessarily increase with age, as well as the well-documented absence of hypertension in aboriginal populations, gives us hope for wider prevention efforts. Consistent with other research, ${ }^{28}$ stage-1 high SBP $(140-159 \mathrm{~mm} \mathrm{Hg})$ does not appear associated with higher CV mortality, which emerges only at stage-2 $(\mathrm{SBP} \geqslant 160 \mathrm{~mm} \mathrm{Hg})$. But even this association disappear when changes over time in PP are taken into account.

Data from the Framingham study shows that DBP is the best CV risk predictor among those younger than age 50, that among age 50-59 a transition stage exists where SBP, DBP and PP are comparable predictors, but after age 60 , the DBP is inversely correlated with risk, making the PP a superior predictor than isolated SBP. ${ }^{14}$ Our longitudinal data similarly showed that among older adults, aging had little effect on SBP levels, but it had a clear effect of widening PP. Evidence shows that increase in PP is correlated with heart failure frequency ${ }^{13}$ and global mortality, clarifying discrepancies that are seen at the population level with DBP. ${ }^{29}$

Our data, however, did not support recently reported findings from the Framingham study showing that the higher risk of adverse CV events among elderly patients with wide PP are amplified by (or even limited to individuals with) low DBP $(<70 \mathrm{~mm} \mathrm{Hg})$ and that CV risk was not greater in people taking antihypertensive. ${ }^{30}$ DBP levels neither confounded nor modified the higher CV mortality of wide-PP individuals in these CRELES data.

It is well established that the use of antihypertensive drugs in older, stage-2 hyper-SBP patients can be a good intervention to lower CV death risk, but our data raise concerns about the possibility of widening PP and its negative implications on CV mortality. This can be called a 'hypertension paradox', somewhat similar to the J-curve phenomenon observed in clinical trials and discussed elsewhere. ${ }^{31-33}$ This finding should be weighed against other prevalent comorbid conditions in older adults, such as diabetes, cancer, malnutrition, stroke, dementia, depression and poly-pharmacy that can obscure results in these sub-settings. As we did not analyze specific medications, generalizations must be cautious, but further research is called for.

An evident limitation of this article is that it uses an observational rather than experimental design; thus as discussed above, the results should not be over-interpreted to conclude that the medication has adverse causal effects in some populations (although the results do suggest the importance of further research on that causal question). A causal design is not necessary though to draw our key conclusion: elderly hypertensive patients with wide or increasing PP, especially if receiving TRT, are the highest CV risk group, thus must be carefully assessed, monitored and treated with caution.

A further limitation is inadequate statistical power to detect HRs $<2.0$, despite the substantial sample size. Given the large effect sizes found though, this did not hinder the main analyses of this paper. However, limited statistical power did preclude 
disaggregation to more BP categories or their combinations, as well as further stratifying the sample by age groups, sex, frailty or other characteristics.

Among the strengths of this study are its avoidance of regression dilution bias by including several measures of BP and other variables in three waves, its focus on CV mortality (in contrast with other studies of all-cause mortality), its exclusion of individuals with serious diseases, and its population-based character in a nationally representative probabilistic sample that enhances external validity. Providing data from the rarely studied elderly populations outside of high-income countries is also a strength of this article.

In conclusion, our results strengthen the evidence that PP is an independent risk factor of older adult CV mortality. Being an observational study we cannot attribute causality to our results, but we can underscore the need for further experimental studies that assess the effect of TRTs on PP and subsequent mortality at older ages in diverse populations.

What is known about this topic?

- Blood pressure (BP) and its effect on cardiovascular (CV) outcomes are different at older ages. Hypertension is more common at older ages, but only very high systolic BP (SBP) seems to have adverse outcomes.

- Pulse pressure (PP), measured as the difference between SBP and diastolic BP (DBP), increases at old ages and some literature consider it an independent component of BP with independent effects on CV outcomes.

- There is almost no data about the health risks of high BP among elderly people outside of high-income countries.

What this study adds?

- Aging in elderly Costa Ricans brings, at the population level, little change in SBP, decline in DBP and widening of PP.

- Wide PP, and its longitudinal increase over time, is associated with higher risk of CV death, though only among individuals in our study who were in antihypertensive treatment (TRT). High diastolic and stage-1 high SBP do not have increased risk of CV death in the studied population.

- In older populations, PP must be monitored and antihypertensive TRT regimens must be mindful of high and widening PP.

\section{CONFLICT OF INTEREST}

The authors declare no conflict of interest.

\section{ACKNOWLEDGEMENTS}

The original CRELES panel survey was a project of the Universidad de Costa Rica, carried out by the Centro Centroamericano de Población in collaboration with the Instituto de Investigaciones en Salud (INISA), with funding from Wellcome Trust (Grant No. 072406). We thank CRELES participants, co-investigators, field workers and support personnel. Professor Leonelo Bautista made valuable suggestions to improve an early version of the manuscript.

\section{REFERENCES}

1 Lim SS, Vos T, Flaxman AD, Danaei G, Shibuya K, Adair-Rohani H et al. A comparative risk assessment of burden of disease and injury attributable to 67 risk factors and risk factor clusters in 21 regions, 1990-2010: a systematic analysis for the Global Burden of Disease Study 2010. Lancet 2013; 380(9859): 2224-2260.

2 Del Giudice A, Pompa G, Aucella F. Hypertension in the elderly. J Nephrol 2009; 23 (Suppl. 15): S61-S71.

3 Miranda JJ, Herrera VM, Chirinos JA, Gómez LF, Perel P, Pichardo R et al. Major cardiovascular risk factors in Latin America: a comparison with the United States. The Latin American consortium of studies in obesity (LASO). PloS ONE 2013; 8(1): e54056.
4 Lloyd-Jones DM, Evans JC, Levy D. Hypertension in adults across the age spectrum: current outcomes and control in the community. JAMA 2005; 294(4): 466-472.

5 Alwan A. Global Status Report On Noncommunicable Diseases 2010. World Health Organization: Geneva, 2011.

6 World Health Organization (WHO) A Global Brief On Hypertension: Silent Killer, Global Public Health Crisis, http://www.thehealthwell.info/node/466541 (Accessed on 3 June 2015).

7 Hollenberg NK, Martinez G, McCullough M, Meinking T, Passan D, Preston M et al. Aging, acculturation, salt intake, and hypertension in the Kuna of Panama. Hypertension 1997; 29(part 2): 171-176.

8 Arima H, Tanizaki Y, Kiyohara Y, Tsuchihashi T, Kato I, Kubo M et al. Validity of the JNC VI recommendations for the management of hypertension in a general population of Japanese elderly: the Hisayama study. Arch Intern Med 2003; 163(3): 361-366.

9 Hakala SM, Tilvis RS, Strandberg TE. Blood pressure and mortality in an older population A 5-year follow-up of the Helsinki Ageing Study. Eur Heart J 1997; 18 (6): 1019-1023.

10 van Bemmel T, Gussekloo J, Westendorp RG, Blauw GJ. In a population-based prospective study, no association between high blood pressure and mortality after age 85 years. J Hypertens 2006; 24(2): 287-292.

11 Rosero-Bixby I, Dow WH. Predicting mortality with biomarkers: a populationbased prospective cohort study for elderly Costa Ricans. Popul Health Metr 2012; 10(1): 11.

12 Goldman N, Glei DA, Lin YH, Weinstein M. Improving mortality prediction using biosocial surveys. Am J Epidemiol 2009; 169(6): 769-779.

13 Chae CU, Pfeffer MA, Glynn RJ, Mitchell GF, Taylor JO, Hennekens CH. Increased pulse pressure and risk of heart failure in the elderly. JAMA 1999; 281(7): 634-643.

14 Franklin SS, Larson MG, Khan SA, Wong ND, Leip EP, Kannel WB et al. Does the relation of blood pressure to coronary heart disease risk change with aging? The Framingham Heart Study. Circulation 2001; 103(9): 1245-1249.

15 Franklin SS, Gustin W, Wong ND, Larson MG, Weber MA, Kannel WB et al. Hemodynamic patterns of age-related changes in blood pressure: the Framingham Heart Study. Circulation 1997; 96(1): 308-315.

16 CRELES: Costa Rican Longevity and Health Aging Study, 2005 (Costa Rica Estudio de Longevidad y Envejecimiento Saludable): Sampling and Methods No. ICPSR26681-v2) (Internet). Inter-university Consortium for Political and Social Research http://www.icpsr.umich.edu/icpsrweb/NACDA/ studies/26681/documentation. Retrieved on 15 January 2013. 2010 (cited on 15 January 2013). Available from http://www.icpsr.umich.edu/icpsrweb/NACDA/ studies/26681/documentation.

17 World Development Indicators (Internet). Retrieved on 16 October 2013. (cited on 16 October 2013). Available from:http://databank.worldbank.org/data/ views/reports/tableview.aspx.ohttp://databank.worldbank.org/data/views/ reports/tableview.aspx.

18 Brenes-Camacho G, Rosero-Bixby L. Differentials by socioeconomic status and institutional characteristics in preventive service utilization by older persons in Costa Rica. J Aging and Health 2009; 21(5): 730-758.

19 Rosero-Bixby L. The exceptionally high life expectancy of Costa Rican Nonagenarians. Demography 2008; 45(3): 673-691.

20 Méndez-Chacón E, Santamaría-Ulloa C, Rosero-Bixby L. Factors associated with hypertension prevalence, unawareness and treatment among Costa Rican elderly. BMC Public Health 2008; 8: 275.

21 Ostchega Y, Dillon CF, Hughes JP, Carroll M, Yoon S. Trends in hypertension prevalence, awareness, treatment, and control in older US adults: data from the National Health and Nutrition Examination Survey 1988 to 2004. J Am Geriatr Soc 2007; 55(7): 1056-1065.

22 Grim CE, Grim CM. Omron HEM-711 DLX home blood pressure monitor passes the European Society of Hypertension International Validation Protocol. Blood Press Monit 2008; 13 (4): 225-226.

23 Franklin SS. Ageing and hypertension: the assessment of blood pressure indices in predicting coronary heart disease. Journal of hypertension. J Hypertens 1999; 17 (Suppl. 5): S29-S36.

24 Kalantar-Zadeh K, Block G, Horwich T, Fonarow GC. Reverse epidemiology of conventional cardiovascular risk factors in patients with chronic heart failure. $J \mathrm{Am}$ Coll Cardiol 2004; 43(8): 1439-1444.

25 Kom EL, Graubard Bl, Midthune D. Time-to-event analysis of longitudinal follow-up of a survey: choice of the time-scale. Am J Epidemiol 1997; 145(1): 72-80.

26 Bongaarts J, Feeney G. How long do we live? Popul Dev Rev 2002; 28(1): 13-29.

27 Fletcher RH, Fletcher SW, Fletcher GS. Clinical epidemiology: the essentials. 5th edn Lippincott Williams \& Wilkins, 2014.

28 Tavares A. Pharmacotherapy for mild hypertension. Sao Paulo Med J 2012; 130(6): 417-418. 
29 Glynn RJ, Chae CU, Guralnik JM, Taylor JO, Hennekens CH. Pulse pressure and mortality in older people. Arch Int Med 2000; 160(18): 2765-2772.

30 Franklin SS, Gokhale SS, Chow VH, Larson MG, Levy D, Vasan RS et al. Does low diastolic blood pressure contribute to the risk of recurrent hypertensive cardiovascular disease events? The Framingham Heart Study. Hypertension 2015; 65(2): 299-305.

31 Grassi G, Quarti-Trevano F, Dell'Oro R, Mancia G. The "J curve" problem revisited: old and new findings. Curr Hypertens Rep 2010; 12(4): 290-295.

32 Park CG, Lee JY. The significance of the j-curve in hypertension and coronary artery diseases. Korean Circ J 2011; 41(7): 349-353.
33 Banach M, Michalska M, Kjeldsen SE, Malyszko J, Mikhailidis DP, Rysz J. What should be the optimal levels of blood pressure: does the J-curve phenomenon really exist? Expert Opin Pharmacother 2011; 12(12): 1835-1844.

\section{(c) (i)}

This work is licensed under a Creative Commons Attribution 4.0 International License. The images or other third party material in this article are included in the article's Creative Commons license, unless indicated otherwise in the credit line; if the material is not included under the Creative Commons license, users will need to obtain permission from the license holder to reproduce the material. To view a copy of this license, visit http://creativecommons.org/licenses/ by/4.0/

Supplementary Information accompanies this paper on the Journal of Human Hypertension website (http://www.nature.com/jhh). 